\title{
Growth of large single MOF crystals and effective separation of organic dyes
}

\author{
Lina Li, ${ }^{\text {a }}$ Fuxing Sun, ${ }^{\text {a Jiangtao Jia, }}$, Tsolmon Borjigin, ${ }^{\text {a }}$ and Guangshan Zhu ${ }^{* a b}$
}

Through the optimization of synthesis conditions, we obtained large $\mathrm{Cu}_{3}(\mathrm{BTC})_{2}$ crystals with the diameter of $2 \sim 4 \mathrm{~mm}$. Such large crystals could be utilized as "chromatographic columns" for effective separation of organic dyes such as thionine (TH) and Pyronin B (PB). It was found that the concentration of hydrion was the key factor to get the large pure crystals. This strategy could be used to grow other hydrophilic MOFs.

\section{Introduction}

Metal-organic frameworks (MOFs) representing an interface between organic and inorganic compounds ${ }^{1}$ were discovered at the end of 20th century which started a new era and brought new thoughts and ideas to the field of the whole chemistry. ${ }^{2}$ The combination of organic ligands as linkers with metal-oxo clusters $^{3}$ as nodes to metal-organic frameworks is currently a field of high activity. ${ }^{4}$ MOFs, established as a new class of porous crystalline materials, provide almost the highest porosities $^{5}$ and surface areas on a weight-specific basis so far. Thanks to its low volume fraction, MOFs are widely regarded as promising materials for applications, such as gas adsorption ${ }^{6}$, storage $^{7}$, separation ${ }^{8}$ chemical sensing devices ${ }^{9}$, and catalysis. ${ }^{7,10}$

In the hot research field of crystal separation and chromatograph $^{11}$, a host of applications utilized MOF's physical absorption as the main principle ${ }^{12}$, and more importantly its regular and unique pore channels can be taken advantages as stationary phase. Especially, when the size of MOF crystals were promoted to millimeter level, the advantages of large single MOF crystals would appear, such as the direct separation application and exploration of separation mechanism on the visible level. It is revealed that large single MOF crystals in millimeter range can be used in chromatograph and in microscopic response. Researches about large single MOF crystals are of significant value in the mechanism exploration of molecule diffusion in MOFs. ${ }^{13,14}$ However, it is difficult to grow large single MOF crystals in millimeter level, and generally the crystals obtained are in the micrometer $(\mu \mathrm{m})$ level. Until now, only MOF-5 large single crystals under millimeter level have been reported, whose average sizes was around $2 \times 2 \times 1(\mathrm{~mm}) .{ }^{15}$ There are still no reports about the growth mechanism of large single MOF crystals. Hence, how to obtain large single MOF crystals has become an important issue to be solved. $\mathrm{Cu}_{3}(\mathrm{BTC})_{2}$, as another classic MOF material, is well-known because of its excellent porosity. Moreover, $\mathrm{Cu}_{3}(\mathrm{BTC})_{2}$ is more stable than MOF-5, which is of more benefit for research and practical applications. It possesses a three-dimensional system of channels with a pore size of $1 \mathrm{~nm}$

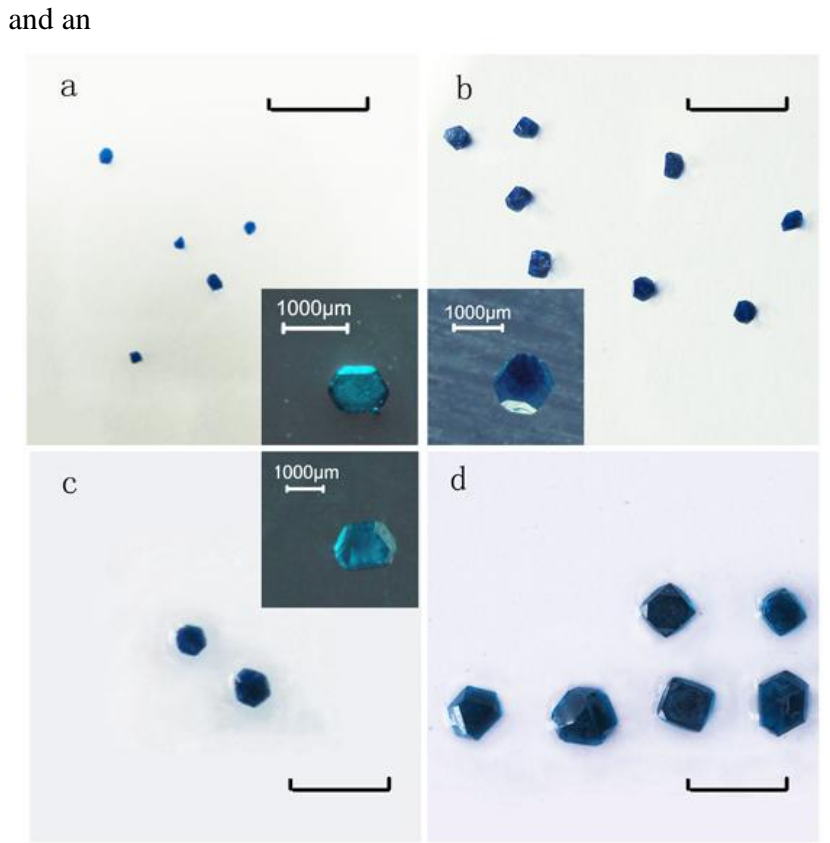

Figure 1. The digital photographs of $\mathrm{Cu}_{3}(\mathrm{BTC})_{2}$ single crystals obtained with the volume ratios of DMF/nitric acid of (a) 4:1, (b) 1:1, (c) 1:2 and

(d) 1:4, respectively. All black scale bars $=5 \mathrm{~mm}$. (insert: magnified photographs by optical microscope)

accessible porosity of about $40 \%$ in the solid. ${ }^{16}$ Another pore feature of $\mathrm{Cu}_{3}(\mathrm{BTC})_{2}$ is its exposed metal sites in quantity which make it possess different characters over other MOFs such as its preferential adsorption of quadrupole molecules ${ }^{17}$. The exposed metal sites also lead to adsorptive separation for some small molecules. ${ }^{18,19}$ Besides its high Lewis acidity makes it more suitable for catalytic purposes. ${ }^{20}$ For example, the membrane of $\mathrm{Cu}_{3}(\mathrm{BTC})_{2}$ shows a great potential for hydrogen purification and separation. ${ }^{21}$ Herein, we report the large $\mathrm{Cu}_{3}(\mathrm{BTC})_{2}$ crystals with the diameter of $2 \sim 4 \mathrm{~mm}$ obtained through the optimization of synthesis conditions (Figure 1). The large single $\mathrm{Cu}_{3}(\mathrm{BTC})_{2}$ crystals can be used to effectively separate mixtures of organic dyes by acting force instead of dye molecule sizes. Taking the advantages of organic dyes as markers, large single $\mathrm{Cu}_{3}(\mathrm{BTC})_{2}$ crystals shows potential application value in the area of amine separation. Moreover, a crystal growth mechanism is proposed to explain the formation of large $\mathrm{Cu}_{3}(\mathrm{BTC})_{2}$ crystal.

\section{Experimental}

2.1 Preparation of large $\mathrm{Cu}_{3}(\mathrm{BTC})_{2}$ crystals 
In a typical process, $\mathrm{Cu}\left(\mathrm{NO}_{3}\right)_{2} \cdot 6 \mathrm{H}_{2} \mathrm{O}(0.752 \mathrm{~g})$ was dissolved in DMF $(15 \mathrm{ml})$ in a $50 \mathrm{ml}$ beaker (beaker A). The benzene tricarboxylate $(0.422 \mathrm{~g})$ was dissolved in DMF $(10 \mathrm{ml})$ in another beaker (beaker B). After 20 minutes' stirring at $25{ }^{\circ} \mathrm{C}$ respectively, mixed $3 \mathrm{ml}$ copper nitrate solution from beaker A with $2 \mathrm{ml}$ BTC solution from beaker B in a $50 \mathrm{ml}$ beaker. Then added $2 \mathrm{~mol} / \mathrm{L}$ nitric acid $(20 \mathrm{ml})$ into the $25 \mathrm{ml}$ beaker and mixed it with slight shake. Covered the beaker with plastic wrap tightly and made sure of its leakproofness. Transferred it to a freezing environment for about 1 day before transferred to a drying oven of $85{ }^{\circ} \mathrm{C}$, where kept it for the next 7 days.

Before the dye separation, $\mathrm{Cu}_{3}(\mathrm{BTC})_{2}$ crystals were soaked in dichloromethane and then get rid of solvent molecules in $403 \mathrm{~K}$ vacuum conditions. Then $0.01 \mathrm{~mol} \mathrm{TH}$ and $0.01 \mathrm{~mol} \mathrm{~PB}$ were added into a $250 \mathrm{ml}$ bottle and $200 \mathrm{ml}$ ethanol was added to dissolve two dyes. Then put several $\mathrm{Cu}_{3}(\mathrm{BTC})_{2}$ crystals in the solution and kept the bottle standing with the cover tight. Then the separation result could be observed with Laser Confocal Scanning Fluorescence Microscopy.

\subsection{Characterization}

Powder X-ray diffractions (XRD) were carried out with $\mathrm{Cu}-\mathrm{K} \alpha(\lambda$ $=1.5418 \AA$ ) at $40 \mathrm{kV}$ on Scintag X1 diffractometer, $35 \mathrm{~mA}$. The FCFM photographs were from Laser Confocal Scanning Fluorescence Microscopy FV1000. All digital photographs were taken by Sony w630 and Canon D500, while the magnified photographs were taken by operating camera LED 1000 from Leica Microsywtems.

\section{Results and discussion}

\subsection{Preparation of $\mathrm{Cu}_{3}(\mathrm{BTC})_{2}$}

$\mathrm{Cu}_{3}(\mathrm{BTC})_{2}$ was firstly synthesized in a solution of $\mathrm{Cu}\left(\mathrm{NO}_{3}\right)_{2} \cdot 6 \mathrm{H}_{2} \mathrm{O}$ and trimesic acid under solvothermal conditions. ${ }^{16}$ The technique consists of hydrothermal formation of $\mathrm{Cu}_{3}(\mathrm{BTC})_{2}$ at $383 \mathrm{~K}$ from a premixed ethanolic aqueous solution ( $1: 1 \mathrm{vol})$ that contained trimesic acid and $\mathrm{Cu}\left(\mathrm{NO}_{3}\right)_{2} \cdot 6 \mathrm{H}_{2} \mathrm{O}$ over 18 hours. Other works showed the reaction temperature could be adjusted from 383 to $425 \mathrm{~K}$ to synthesize $\mathrm{Cu}_{3}(\mathrm{BTC})_{2}$ crystals. ${ }^{22} \mathrm{It}$ was also reported that the effect of synthesis conditions on the morphology and crystal size of $\mathrm{Cu}_{3}(\mathrm{BTC})_{2}$ could be determined through optimizing the synthetic conditions. ${ }^{23}$ We prepared the $\mathrm{Cu}_{3}(\mathrm{BTC})_{2}$ crystals according to these methods. The crystal sizes of $\mathrm{Cu}_{3}(\mathrm{BTC})_{2}$ obtained were usually limited between 100 and 300 $\mu \mathrm{m}$. On those bases, we investigated impact factors on the crystal size and optimize the synthesis conditions.

To obtain large $\mathrm{Cu}_{3}(\mathrm{BTC})_{2}$ crystals, firstly, we chose DMF and water as solvent due to preliminary preparation experience. Different reaction ratios and temperatures had been explored, which showed temperature was an important factor in controlling the crystal size and morphology for entropic reasons. ${ }^{17} \mathrm{~A}$ series of experiments were carried out from $333 \mathrm{~K}$ to $443 \mathrm{~K}$, which showed that $358 \mathrm{~K}$ is the optimized temperature for crystal growth. Subsequently, different amounts of acid were used in the reaction system. Surprisingly, the size of $\mathrm{Cu}_{3}(\mathrm{BTC})_{2}$ crystals began to grow beyond expectation. It is apparent that the size increased with the proportion of acid in the system. The diameter of the largest crystals could reach $4 \mathrm{~mm}$ (Figure 1d) when the volume percentage of nitric acid is about $80 \%$. At the same time, the crystallization time extended from 48 hours to one week.

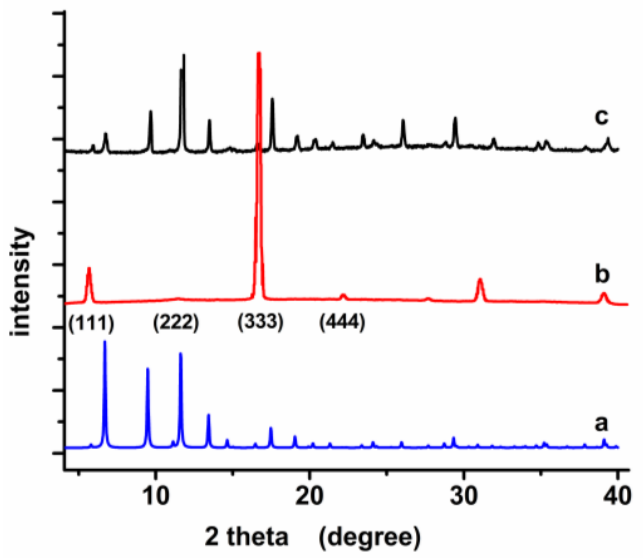

Figure 2. XRD patterns of: (a) calculated from $\mathrm{Cu}_{3}(\mathrm{BTC})_{2}$ structure; (b) one single crystal from the hexagon face (c) powder ground from single crystals.

However, when the proportion of nitric acid in the system is over $85 \%$, only the inorganic salt $\mathrm{Cu}\left(\mathrm{NO}_{3}\right)_{2}$ could be obtained.

During that process, the $\mathrm{pH}$ changed greatly. Before the heating part, the $\mathrm{pH}$ in this system was below zero, but after that, it increased to 6.5 , which proved the neutralization in the reaction system.

\subsection{Analysis of crystal purity}

As shown in Figure 2, the XRD pattern of the powder ground from large single crystals (Figure 2c) agrees very well with the calculated one (Figure 2a), which indicates a pure phase of $\mathrm{Cu}_{3}(\mathrm{BTC})_{2}$. Figure $2 \mathrm{~b}$ shows the XRD pattern of one crosssection of a single crystal with the peaks at $2 \theta=5.806^{\circ}, 11.627^{\circ}$, $17.479^{\circ}$ and $23.377^{\circ}$ which can be indexed to (111), (222), (333), and (444) respectively. It demonstrated that the direction of the cross-section is the [111] direction corresponding to the hexagon face of the crystal morphology, which coincided with the measuring conditions. These results show that the large crystal was absolutely pure and single with high quality.

\subsection{Effective dye separation}

Encouraged by the high quality of the large $\mathrm{Cu}_{3}(\mathrm{BTC})_{2}$ single crystals and dyes could be absorbed through immersion ${ }^{24,25}$, organic dye separation experiments were conducted. Organic dyes, thionine $(\mathrm{TH})$ and Pyronin $\mathrm{B}(\mathrm{PB})$, were chosen for their similar molecule sizes and fluorescence property. Both the sizes of two dyes are 0.8-0.9 $\mathrm{nm}$ in length and 0.4-0.5 nm in width, which are appropriate for the $1 \mathrm{~nm}$ pore channels of $\mathrm{Cu}_{3}(\mathrm{BTC})_{2}{ }^{16}$ The main difference between these two dyes is that the end groups of $\mathrm{TH}$ are two amino groups while those of $\mathrm{PB}$ are diethyl-amino groups instead. In the term of fluorescence property, excitation and emission of the two dyes occur at different wavelengths (excitation/emission: $543 \mathrm{~nm} / 570-615 \mathrm{~nm}$ for PB; $633 \mathrm{~nm} / 670-770 \mathrm{~nm}$ for TH). ${ }^{15}$ Therefore, TH and PB can be identified without mutual interference. $\mathrm{PB} / \mathrm{TH}$ of fluorescent dyes were chosen to be separated in ethanol solution by the large $\mathrm{Cu}_{3}(\mathrm{BTC})_{2}$ crystals.(Figure 3a) The separation results were characterized with the help of fluorescence confocal microscopy (FCFM). Because of the point-by-point excitation and detection, 
the transport and distribution process can be observed by microscopy, especially the inner part of single crystals. Due to the
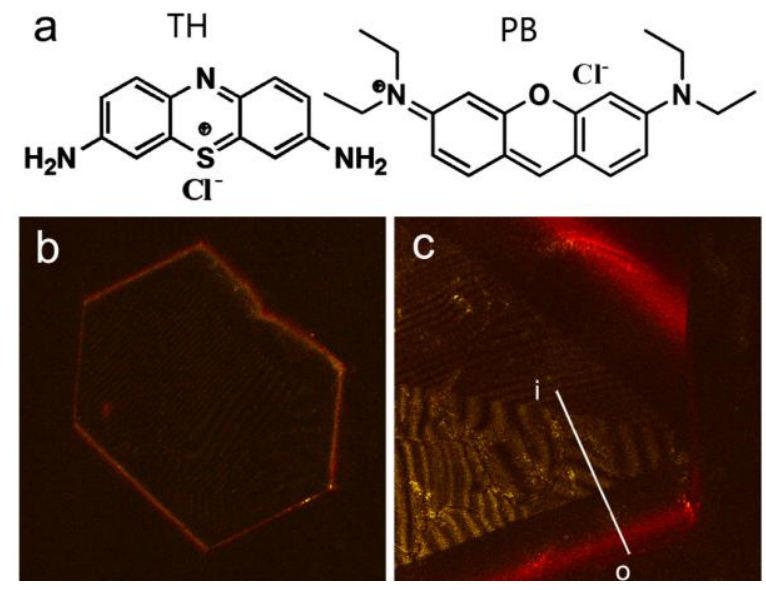

Figure 3. (a) Chemical structures of $\mathrm{TH}$ and $\mathrm{PB}$; (b, c) photographs from FCFM revealing optical side-on views of the $\mathrm{Cu}_{3}(\mathrm{BTC})_{2}$ crystals separating mixture of TH (red) and PB (yellow) after 3 days (b) and 7 days (c) immersion. The "o" stands for the outside of the crystal while "i" stands for the inner part of it.

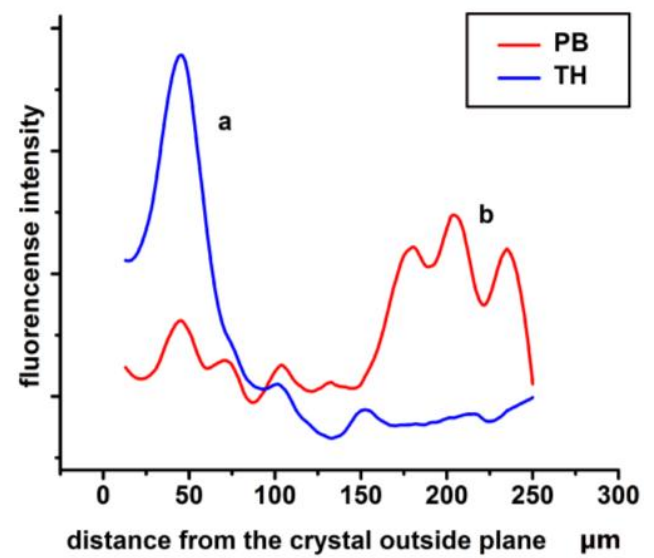

Figure 4. Experimental concentration profiles measured by FCFM during separation of $\mathrm{TH}$ (a) and $\mathrm{PB}$ (b) dyes from the outside (o) to the inside (i) in the Figure 3 in a $\mathrm{Cu}_{3}(\mathrm{BTC})_{2}$ crystal after 7 days separation.

fact that the dyes and other separable materials get into the crystals by free diffusion, so the crystals can be reused after soaking. The experimental results indicated that more than $99 \%$ of the dyes had been eliminated after 3 days' soaking. In this way, the use of $\mathrm{Cu}_{3}(\mathrm{BTC})_{2}$ as effective separation medium is not only feasible but also economical and environmental.

Figure 3 shows diffusion results of $\mathrm{TH}$ and $\mathrm{PB}$ in a $\mathrm{Cu}_{3}(\mathrm{BTC})_{2}$ crystal after 7 days immersing in their ethanol solution. It is demonstrated that the PB had diffused into the inner part of the crystal, while TH still stays at the outer layer. The concentration profiles of the PB and TH dyes at 7 days' separation are presented in Figure 4, showing the different dyes can be separated from each other. The distance between the two bands of dye molecules in one $\mathrm{Cu}_{3}(\mathrm{BTC})_{2}$ crystal was about $160 \mu \mathrm{m}$. Normally, small molecules should diffuse faster than bigger ones. In this case, the larger one $\mathrm{PB}$, however, diffused further in the crystals, which is opposite to the separation results of $\mathrm{PB}$ and $\mathrm{TH}$ in MOF-5 crystals. ${ }^{15}$ It can be explained with the unique functions of exposed metal sites, ${ }^{26}$ such as particular complexation. With the large single crystals of MOF-5, it has been proved that the diffusion progress in MOFs is related with the acting force. ${ }^{14}$

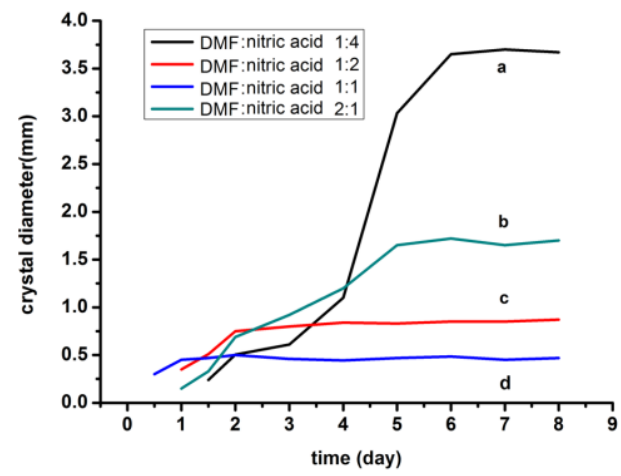

Figure 5. The growth curves of $\mathrm{Cu}_{3}(\mathrm{BTC})_{2}$ crystals with the composition ratio ( DMF : nitric acid) at 1:4 (a), 1:2 (b), 1:1 (c), 2:1(d) respectively. With different composition of the reaction system, crystals would reach their specific maximum average size at different time.

Unincorporated dyes were rapidly transported through its channels while the dyes with complexing action would be restrained longer in the cages. ${ }^{27}$ Unlike MOF-5 there are a large amount of unsaturated copper ion sites in $\mathrm{Cu}_{3}(\mathrm{BTC})_{2}$ crystals. It is assumed that the unsaturated copper sites in the framework of $\mathrm{Cu}_{3}(\mathrm{BTC})_{2}$ had stronger interaction with $\mathrm{TH}$, in which the electron pairs on amino groups were more exposed than those on diethylamino groups of PB.

\subsection{Growth mechanism of MOF crystals}

In a series of experiments with different acids, except the ones with coordination effect, single $\mathrm{Cu}_{3}(\mathrm{BTC})_{2}$ crystals could be obtained. (see supporting information) During the synthesis, the amount of hydrion played a key role to obtain large single crystals, just like the suppresser in the growth of large single zeolite crystals. $^{28,29}$ The large amount of hydrion in the system would inhibit the deprotonation of $\mathrm{H}_{3} \mathrm{BTC}$. According to the formula, $\mathrm{K}_{\mathrm{a}}=\left[\mathrm{H}^{+}\right]^{3}\left[\mathrm{BTC}^{3-}\right] /\left[\mathrm{H}_{3} \mathrm{BTC}\right]$, with the increase of hydrion concentration, the quantity of $\mathrm{BTC}^{3-}$ anion would decrease. Therefore, it was hard to provide adequate coordinate anions for $\mathrm{Cu}_{3}(\mathrm{BTC})_{2}$ crystal growth while crystallization time was extended from 48 hours to 7 days, shown in Figure 5. Low anion content suppressed the opportunity of generating new nucleus. In this way, $\mathrm{Cu}_{3}(\mathrm{BTC})_{2}$ crystals were offered with an appropriate chance to grow to a large size. On the other hand, MOF materials were generally metastable in acid condition because the hydrion in solvent would break coordinate bond down (see supporting information). When the concentration of hydrion reached a certain level, the hydrion would attack the coordinate bond due to its great ability to grab electron. Hence the hydrion with higher electronegativity might interfere the coordinate stability of atoms with lower electronegativity (e.g. $\mathrm{Cu}^{2+}$ ) from receiving lone pair electrons ${ }^{30}$. In addition, the acid condition could make DMF, the main solvents in this system, decomposed gradually into dimethylamine when heated to certain temperature. $^{31}$ And in the system the dimethylamine could gradually neutralize the acid in the reaction system. In this way, the two effects of acid above could be weakened little by little during the crystal growing process, thus a delicate synthetic 
environment with both the concentration of $\mathrm{BTC}^{3-}$ and the number of new nuclei balanced could probably be created, which might offer an appropriate environment for the crystals to grow.

\section{Conclusions}

In conclusion, large single MOF crystals are of great significance to study the separation process and growth mechanism of MOFs. Through the optimization of synthesis conditions, large $\mathrm{Cu}_{3}(\mathrm{BTC})_{2}$ crystals with the largest diameter of $4 \mathrm{~mm}$ have been obtained. Such large crystals could be utilized as "chromatographic columns" for effective separation application. The large single $\mathrm{Cu}_{3}(\mathrm{BTC})_{2}$ crystals can be used to effectively separate mixtures of organic dyes, PB and TH. Due to the complexation of amino-group and unsaturated copper sites, the unique pore features of $\mathrm{Cu}_{3}(\mathrm{BTC})_{2}$ exhibited a different separation behavior of the PB and TH dyes to MOF-5. It is also found that the concentration of hydrion is the key factor to get the biggest pure crystals. This strategy could be used to grow other hydrophilic MOFs.

\section{Notes and references}

${ }^{a}$ State Key Laboratory of Inorganic Synthesis and Preparative Chemistry, College of Chemistry, Jilin University, Changchun, China (130012).

Fax:+860431 85168331; Tel: +860431 85168887. E-mail:

zhugs@jlu.edu.cn

${ }^{b}$ Queensland Micro- and Nanotechnology Centre, Griffith University,

Queensland, 4111, Australia

$\dagger$ Electronic Supplementary Information (ESI) available: [details of any]

1. N. Stock and T. Bein, Angewandte Chemie International Edition, 2004, 43, 749-752.

2. J. Kim, B. Chen, T. M. Reineke, H. Li, M. Eddaoudi, D. B. Moler, M. O'Keeffe and O. M. Yaghi, Journal of the American Chemical Society, 2001, 123, 8239-8247.

3. H. Li, M. Eddaoudi, M. O'Keeffe and O. M. Yaghi, Nature, 1999, 402, 276-279.

4. , !!! INVALID CITATION !!!

5. H. Furukawa, N. Ko, Y. B. Go, N. Aratani, S. B. Choi, E. Choi, A. Ö. Yazaydin, R. Q. Snurr, M. O'Keeffe and J. Kim, Science, 2010, 329, 424-428.

6. J. L. C. Rowsell, E. C. Spencer, J. Eckert, J. A. K. Howard and O. M. Yaghi, Science, 2005, 309, 1350-1354.

7. D. J. Collins and H. C. Zhou, J. Mater. Chem., 2007, 17, 3154-3160.

8. J. S. Seo, D. Whang, H. Lee, S. I. Jun, J. Oh, Y. J. Jeon and K. Kim, Nature, 2000, 404, 982-986.

9. S. Han, Y. Wei, C. Valente, R. S. Forgan, J. J. Gassensmith, R. A. Smaldone, H. Nakanishi, A. Coskun, J. F. Stoddart and B. A. Grzybowski, Angewandte Chemie, 2011, 123, 290-293.

10. D. Farrusseng, S. Aguado and C. Pinel, Angewandte Chemie International Edition, 2009, 48, 7502-7513.

11. A. S. Münch, J. Seidel, A. Obst, E. Weber and F. O. R. L. Mertens, Chemistry-A European Journal, 2011, 17, 10958-10964.

12. S. Ma and H. C. Zhou, Chem. Commun., 2009, 46, 44-53.

13. T. C. Li, A. M. Spokoyny, C. She, O. K. Farha, C. A. Mirkin, T. J. Marks and J. T. Hupp, Journal of the American Chemical Society, 2010, 132, 4580-4582.

14. S. Han, T. M. Hermans, P. E. Fuller, Y. Wei and B. A. Grzybowski, Angewandte Chemie International Edition, 2012, 51, 2662-2666.
15. S. Han, Y. Wei, C. Valente, I. Lagzi, J. Gassensmith, A. Coskun and J. Stoddart, J. Am. Chem. Soc, 2010, 132, 16358.

16. S. S. Y. Chui, S. M. F. Lo, J. P. H. Charmant, A. G. Orpen and I. D. Williams, Science, 1999, 283, 1148-1150.

17. Q. M. Wang, D. Shen, M. Blow, M. L. Lau, F. R. Fitch and S. Deng, Google Patents, 2002.

18. R. Babarao, J. Jiang and S. I. Sandler, Langmuir, 2008, 25, 52395247.

19. O. Zybaylo, O. Shekhah, H. Wang, M. Tafipolsky, R. Schmid, D. Johannsmann and C. Wöll, Physical Chemistry Chemical Physics, 2010, 12, 8092-8097.

20. L. Alaerts, E. Séguin, H. Poelman, F. Thibault - Starzyk, P. A. Jacobs and D. E. De Vos, Chemistry-A European Journal, 2006, 12, 7353-7363.

21. H. Guo, G. Zhu, I. J. Hewitt and S. Qiu, Journal of the American Chemical Society, 2009, 131, 1646-1647.

22. A. Vishnyakov, P. I. Ravikovitch, A. V. Neimark, M. Bülow and Q. M. Wang, Nano Letters, 2003, 3, 713-718.

23. J. Gascon, S. Aguado and F. Kapteijn, Microporous and Mesoporous Materials, 2008, 113, 132-138.

24. K. Gedrich, M. Heitbaum, A. Notzon, I. Senkovska, R. Fröhlich, J. Getzschmann, U. Mueller, F. Glorius and S. Kaskel, Chemistry-A European Journal, 2011, 17, 2099-2106.

25. Y. Li, A. Pang, C. Wang and M. Wei, Journal of Materials Chemistry, 2011, 21, 17259-17264.

26. M. Dincă and J. R. Long, Angewandte Chemie International Edition, 2008, 47, 6766-6779.

27. Y. Q. Lan, H. L. Jiang, S. L. Li and Q. Xu, Advanced Materials, 2011, Nov 16, 23, 5015-20

28. G. Zhu, S. Qiu, J. Yu, Y. Sakamoto, F. Xiao, R. Xu and O. Terasaki, Chemistry of materials, 1998, 10, 1483-1486.

29. S. Qiu, J. Yu, G. Zhu, O. Terasaki, Y. Nozue, W. Pang and R. Xu, Microporous and Mesoporous Materials, 1998, 21, 245-251.

30. R. G. Parr and R. G. Pearson, Journal of the American Chemical Society, 1983, 105, 7512-7516.

31. M. Grela, V. Amorebieta and A. Colussi, The Journal of Physical Chemistry, 1985, 89, 38-41. 